Inventing Polymer Science: Staudinger, Carothers and the Emergence of Macromolecular Chemistry

Yasu Furukawa

(University of Pennsylvania Press,

Philadelphia, 1998)

$x i+310$ pages. $\$ 49.95$

ISBN 0-8122-3336-0

This is one of the most impressive works in the history of science that it has been my good fortune to read. In the early 1980 s the Japanese author was a student of the history of science at the University of Oklahoma, advised by an excellent historian, Mary Jo Nye; before that he had been a "practicing chemist." Since he received his $\mathrm{PhD}$ degree, he has continued devotedly pursuing the theme of this book, and has served for one year as a guest of the Chemical Heritage Foundation in Philadelphia. He is now professor of the history of science at the College of Engineering of Tokyo Denki University. He has made very extensive use of original sources and archives of many kinds. So the book has had a very long gestation.

Hermann Staudinger (1881-1965) was a resolute, indeed stubborn, German organic chemist who became obsessed by the study of organic polymers. His great achievement, in Furukawa's words, was that he successfully "raised the banner of revolt against the [then] current colloidalist interpretation of polymers." Organic chemists for many years refused to accept that molecules held together by regular covalent valencies could have molecular weights which were both variable and very large, and insisted that polymers consisted of small molecules held together by "secondary valencies" in colloidal aggregates, an insistence that retarded the development of polymer science by more than a decade. After years of research and controversy, his conception of macromolecules, based upon his experiments in addition to polymerization, was finally accepted at a Faraday Discussion in London in 1935.

Wallace Hume Carothers (1896-1937) was an American organic chemist who left Harvard University to work at DuPont; he was the principal creator of industrial polymer synthesis and exploitation through his exploration of condensation polymerization that led to the discovery and manufacture of nylon, among other fibers. He was a depressive who took his own life at the age of 41 .

This bald summary of the facts around which this history is woven can give no impression of the subtle analysis of intellectual development and controversies (some very bitter) and numerous accounts of the lives and attitudes both of the two princi- pal protagonists and of the many supporting cast in the story. The last chapter analyzes the long-term legacy of Staudinger and Carothers; a particularly interesting part of this is their analysis of the interaction of physical and organic chemistry in the development of polymer science, particularly through the work of Paul Flory in the United States. As Furukawa expresses it, "Physical chemistry was ... proven to be not an inveterate foe of organic chemistry but its essential complementary partner in perfecting the science of macromolecules."

Anyone who is professionally concerned with polymers, and anyone who wants to know how science contributed to the evolution of a major industry, is advised to read this book.

Reviewer: Robert W. Cahn is a physical metallurgist turned materials scientist, currently attached in nominal retirement to Cambridge University. $\mathrm{He}$ is in the middle of writing a historical book, The Coming of Materials Science. He is a member of the Editorial Board of MRS Bulletin and of its Book Review Board.

\section{The Scientist as Consultant: Building New Career Opportunities} Cart J. Sindermann and Thomas K. Sawyer (Plenum Trade, New York, 1997)

xiv + 341 pages, $\$ 29.95$

ISBN 0-306-45637-0

Many materials scientists and engineers find that one of the greatest rewards of their work is the opportunity to tackle technical challenges with practical applications. This book looks at a form of employment that allows the practitioner to become involved in real-world problems on an ongoing basis-consulting.

Perhaps no word characterizes consulting as well as "variety." Many university professors or retirees consult on a parttime basis. Others choose consulting, either immediately after completing their education or later in life, as a full-time career. The possible venues for consulting range from working as an individual or in a small group to employment in a large "mega" consulting firm.

This book gives an excellent overview of consulting for anyone contemplating it as a career or part-time occupation. The advantages as well as disadvantages of this line of work are clearly identified and are described in sufficient depth to give the reader a good feel for what such a career might involve. The various forms of consulting are also well characterized. Possible scenarios for making the transition from school or another career to consulting, including the very important issue of how to try consulting without making an irrevocable commitment to an un- known career are also well covered.

In summary, this volume is an important resource for a scientist considering any sort of consulting. The picture that emerges is of a pursuit that is tremendously different from the more traditional career paths of many members of the materials community. At the same time it is shown to be potentially equally rewarding as any of the more typical career venues. This, of course, depends on the priorities and skills (many of which must be nontechnical) of the individual involved. Anyone considering embarking on such a path should proceed with both eyes open.

Reviewer: Julia M. Phillips, a member of the MRS Bulletin Book Review Board, is manager of the Materials Process Computation and Modeling Department at Sandia National Laboratories in Albuquerque, NM. She is also a former President of the Materials Research Society.

\section{Shape Memory Materials}

K. Otsuka and C.M. Wayman, eds. (Cambridge University Press, New York, 1998)

294 pp., $\$ 180.00$

\section{ISBN 0-080-42129-6}

In less than a decade, shape memory alloys have moved from being topics for academic research to broad application in industrial, consumer product, and medical fields. Information on the use of these fascinating materials has been confined to the published proceedings of conferences such as the International Conference on Martensite and the Conference on Shape Memory and Superelastic Technology, as well as the proceedings of various conferences on smart materials and adaptive structures. The present volume uniquely provides both a detailed description of metallurgical processes that are involved in the shape memory effect and related phenomena such as pseudoelastic behavior and damping, but in addition gives a good overview of shape memory alloy processing, industrial applications, and device design. The chapters on shape memory polymers and ceramics provide an insight into what these materials offer as actuators for various systems.

The first part of the book concisely describes the basic physical metallurgy of thermoelastic martensitic alloys, followed by a detailed description of the metallurgy and properties of the three important shape memory alloy systems: nickel-titanium, copper-based alloys, and ferrous shape memory alloys. These three chapters are written by well-known Japanese scientists with substantial backgrounds and publications in these topics, which is not surprising given that the large body of literature 
on shape memory phenomena has been generated by academic institutions in Japan. For the reader unfamiliar with the metallurgy of shape memory alloys, these chapters, almost one half of the text, provide a very sound introduction to the fundamentals of the shape memory effect.

Following a short chapter on the fabrication of shape memory alloys is an excellent description of the alloy characteristics, with valuable information on alloy stability and fatigue properties. Thermodynamic modeling of the shape memory effect is given detailed treatment. This is of particular interest to those interested in integrating constitutive models of the shape memory effect with models for composite materials used in smart materials, a field of rapidly growing interest.

The overview of shape memory ceramics and polymers are brief but very informative and are certainly valuable additions to the overall text for those interested in the design of actuators for demanding applications. The chapter on general applications is very thorough and covers the topic from the earliest industrial uses to the present. This is followed by a valuable discussion of shape memory device design, a topic usually neglected in general treatises on the shape memory effect. Medical applications are fast becoming the most important applications for shape memory alloys and the final chapter, in addition to describing some of the more important ones, also covers the question of corrosion and biocompatibility. Missing from this chapter is a discussion of cardiovascular applications and the uses of shape memory alloys in noninvasive surgical procedures, currently very important.

For the reader interested in gaining an understanding of shape memory effect alloy phenomena and the uses to which these alloys are being put, this text is an excellent introduction, written by some of the foremost experts in this field. Within a short period the volume will also be available in paperback form which should encourage its use in university materials science courses.

Reviewer: L. McD. Schetky has been active in shape memory technology from its earliest days and is chief scientist of Memry Corp. in Connecticut, a major producer of semi-finished shape memory alloy materials and a shape memory alloy device manufacturer.

The following recently published books, relevant to materials science, has come to MRS Bulletin's attention. Some of the books listed here may be reviewed in future issues of MRS Bulletin.

\section{Books}

Advanced Computing in Electron Microscopy, E.J. Kirkland, Plenum Press, New York, 1998. 250 pp., \$72.50, 0-306-45936-1.
Aerosol Processing of Materials, T.T. Kodas and M. Hampden-Smith, Wiley VCH, New York, 1999. 680 pp., \$175.00, ISBN 0-471 24669-7.

Basic Health Physics, J.J. Bevelacqua, John Wiley \& Sons, 1999.559 pp., \$79.95, ISBN 0-471 29711-9.

Beam Effects, Surface Topography, and Depth Profiling in Surface Analysis, A.W. Czanderna, T.E. Madey, and C.J. Powell, eds., Plenum Press, New York, 1998. 430 pp., \$125.00, ISBN 0-306 45896-9.

Ceramic Material Systems with Composite Structures: Towards Optimum Interface Control and Design, N.Takeda, L.M. Sheppard, J-I. Kon, eds., The American Ceramic Society, Westerville, $\mathrm{OH}, 1998.567$ pp., $\$ 100.00$, ISBN 1-574-98065-3.

Chemistry of Hypervalent Compounds, K-Y. Akiba, Wiley-VCH, 1999. 414 pp., $\$ 135.00$, ISBN 0-471 24019-2.

Electrocatalysis, J. Lipowski and P.N. Ross, eds., Wiley-VCH, New York, 1998. 376 pp., $\$ 145.00$, ISBN 0-471-24673-5.

Electron Microscopy 1998, H.A. Calderón Benavides and M.J. Yacamán, Institute of Physics Publishing, Philidelphia, 1998. Vol. 1, 879 pp., Vol. 2, 910 pp; Vol. 3, 805 pp.; Vol. 4, 952 Pp.; $\$ 900.00$, ISBN 0-7503 0568-1.

Electron Transfer, J. Jortner and M. Bixon, John Wiley \& Sons, New York, 1999; Part 1, Vol. 106, 754 pp., \$195.00, ISBN 0-471-25292-1; Part 2, Vol. 107, 755 pp., \$195.00, ISBN 0-471-25292-3.

Fatigue of Materials, $2 d e d$. , S. Suresh, Cambridge University Press, New York, 1998. 679 Pp., \$44.95, ISBN 0 521-57847-7.

The Gap Symmetry and Fluctuation in High-T $T_{c}$ Superconductors, J. Bok, G. Deutscher,

D. Pavuna, and S.A. Wolf, eds., Plenum Press, New York, 1998. 560 pp., $\$ 165.00$.

ISBN 0-306-45934-5.

Handbook of Thermo Optic Coefficients of Optical Materials with Applications, G. Ghosh, Academic Press, San Diego, 1998. 325 pp., \$275.00, ISBN 0-122-81855-5.

The Inorganic Chemistry of Materials: How to Make Things out of Elements, P.J. van der Put, Plenum Press, New York, 1998. 391 pp., \$95.00, ISBN 0-306 45731-8.

Microcluster Physics, $2 d$ ed., S. Sugano and H. Koizumi, Springer-Verlag, New York, 236 pp., \$79.95, ISBN 3-540-63974-8.

Modern Physics for Engineers, J. Singh, John Wiley \& Sons, New York, 1999.379 pp., \$84.95, ISBN 0-471-133044-2.

New Perspectives on Problems in Classical and Quantum Physics, Part 1, P.P. Delsanto, and A.W. Saenz, Gordon \& Breach Science Publishers, Amsterdam, 1998.372 pp., $\$ 79.00$, ISBN 90 5699-548-0.

Nondestructive Characterization of Materials VIII, R.E. Green, Jr., ed., Plenum Press, New York, 1998. 833 pp., \$175.00, ISBN $0306-45900-0$.

Optical Properties of Semiconductor Nanocrystals, S.V. Gaponenko, Cambridge
University Press, New York, 1998. 245 pp., \$64.95, ISBN 0-521 58241-5.

Organic Coatings, $2 d$ ed., Z.W. Wicks, Jr., F.N. Jones, S.P. Pappas, New York, 1999. 630 pp., \$79.95, ISBN 0-471 24507-0.

Phase Diagrams for Zirconium + Zirconium Systems, H.M. Ondik and H.F. McMurdie, The American Ceramic Society, Westerville, $\mathrm{OH}$, 1998. 525 pp., \$150.00, ISBN 1-574 98055-6.

Physical Properties of Liquid Crystals, D. Demus, J. Goodby, G.W. Gray, H.-W.Spiess, V.Vill, eds., Wiley-VCH, New York, 1999. 503 pp., \$120.00, ISBN 3-527-29747-2.

Physics of Materials, Y. Quere, Gordon \& Breach Science Publishers, Amsterdam, 1998. 483 pp., \$25.00, ISBN 90-5699 119-1.

Polymer Handbook, 4th ed., J. Brandup, E.H. Immergut, E.A. Grulke, eds., John Wiley \& Sons, New York, 1999.743 pp., $\$ 295.00$, ISBN 0-471 16628-6.

Practically Speaking: A Dictionary of Quotations on Engineering, Technology and Architecture, C.C. Gaither, A.E. Cavazos Gaither, eds., Institute of Physics Publishing, Philadelphia, 1999. Paper, 369 pp., $\$ 39.00$, ISBN 0-750 30594-0.

Principles of Growth and Processing of Semiconductors, S. Mahajan and K.S. Sree Harsha, MCGraw-Hill, Burr Ridge, IL, 1999. 512 pp., \$92.57, ISBN 0-07-039605-1.

Properties of Amorphous Silicon and Its Alloys, T. Searle, ed., The Institution of Electrical Engineers, London, 1998. 412 pp., \$245.00, ISBN 0 852-6922-8.

Recent Advances in Polymer Chemical Physics, D.C. Prevorsek, ed., Gordon \& Breach Science Publishers, Amsterdam. 1998. 371 pp., \$78.00, ISBN 90-65699 586-3.

Review of Progress in Quantitative Nondestructive Evaluation, Vol. 17A, D.O. Thompson and D.E. Chimenti, eds., Plenum Press, New York, 1998. 1097 pp., \$395.00, ISBN 0-306 45901-9.

Review of Progress in Quantitative Nondestructive Evaluation, Vol. 17B, D.O. Thompson and D.E. Chimenti, eds., Plenum Press, New York, 1998. 2128 pp., \$395.00, ISBN 0-306 45901-9.

Science and Technology of Polymers and Advanced Materials, P.N. Prasad, J.E. Mark, S.H. Kandil, and Z.H. Kafafi, eds., Plenum Press, New York, 1998. 883 pp., \$175.00, ISBN 0-306-45820-9.

Small Particles Technology, J-E. Otterstedt and D.A. Brandreth, Plenum Press, New York, 1998. 524 pp., \$110.00, ISBN 0-306 45935-3.

Structure and Rheology of Complex Fluids R.G. Larson, Oxford University Press, New York, 1999. 663 pp., \$79.95, ISBN 0-19-512197-X.

Structure of Materials, S.M. Allen and E.L. Thomas, John Wiley \& Sons, New York, 1999. 447 pp., \$102.95, ISBN 0-471-00082-5.

Thermodynamics of Crystals, D.C. Wallace, Dover Publications, Mineola, NY, 1972. 484 pp., $\$ 16.95$, ISBN 0-486 40212-6. 